\title{
REFLEXIÓN ACERCA DEL CONTEXTO DE SURGIMIENTO DE POLIITICAS TURISTICAS ¿INDIGENISTAS? EL PROYECTO RED ARGENTINA DE TURISMO RURAL COMUNITARIO (RATURC) DEL MINISTERIO DE TURISMO DE LA NACIÓN (ARGENTINA, 2008-2019) $)^{1}$
}

\section{Thinking About the Context of Emergence of... Indigenist Tourism Policies? The} Project Red Argentina de Turismo Rural Comunitario (RATuRC) of the National Ministry of Tourism (Argentine, 2008-2019)

\section{ELISA LACKO*}

Fecha de recepción: 25 de mayo de 2019 - Fecha de aprobación: 16 de agosto de 2019

\section{Resumen}

En Argentina, las relaciones interétnicas entre los pueblos originarios y el Estado han sido históricamente conflictivas. Estas fueron abordadas, primero, periódica y principalmente desde las políticas públicas sectoriales de seguridad y, en un segundo momento, de desarrollo social. En 2008, el Estado nacional diseñó una política novedosa desde el Ministerio de Turismo, cuyos destinatarios eran los pueblos originarios y/o campesinos. Dado que hasta entonces las políticas indigenistas nacionales no habían sido elaboradas desde este sector y entendiendo la actividad turística como parte de procesos políticos y socioculturales más generales en los cuales cobra sentido, cabe preguntarse cómo es que los pueblos originarios -antes ignorados y ocultados por dicha actividad-cobraron interés para esas políticas sectoriales y cómo fue que estas se decidieron a promover un proceso de valorización turística de esa población. Nuestro objetivo es contextualizar este proceso para poder comprender el papel del Estado como actor central del mismo.

Palabras clave: políticas sectoriales turísticas; políticas indigenistas; turismo en comunidades indígenas; proceso de valorización turística.

\section{Abstract}

In Argentina, governments and native communities have a long-held strained relationship. Indigenous policy was initially and, mainly, framed by the Ministry of Defense. Subsequently, main policies were promoted by Social Affairs Department. It was not until 2008 that the Government designed and implemented a novel program through the Ministry of Tourism to involve native and rural communities in tourism development. Considering this sector has not participated in indigenous policy-making before, and understanding that tourism acquires its meaning in a larger political, social and cultural process, it is worth considering how these communities, ignored and concealed from the tourist activity before, have become an object to sectorial strategies and why state policy has focused on Indigenous tourism development. The aim of this work is to contextualize the process to understand how the State must be a central actor in sustaining the initiative.

Keywords: tourism sectoral policies; indigenous policy and programs; indigenous tourism product; tourism appreciation process.

" Licenciada en Turismo. Profesora en Ciencias Antropológicas, Facultad de Filosofía y Letras, Universidad de Buenos Aires, Buenos Aires, Argentina. Correo-e: elisalacko@hotmail.com 


\section{Introducción}

En el año 2008, ante el inicio de una incipiente actividad turística autogestiva en territorios rurales de algunas comunidades de pueblos originarios y/o campesinas, el Ministerio de Turismo (MINTUR) (gestión 2003-2015) diseñó el proyecto Red Federal de Turismo Rural Comunitario (conocido luego como RATuRC). Con él se proponía apoyar dichas iniciativas para generar inclusión social y desarrollo en esas regiones pauperizadas y alentar la creación de un nuevo atractivo turístico inclusivo-vivencial dentro de estas comunidades (Lacko, 2011). El objetivo del proyecto se enunciaba así:

\section{Promover el desarrollo local comunitario y el fortale- cimiento de pueblos originarios y sus descendientes, residentes en espacios rurales, mediante el desarrollo de la actividad turística sustentable, identificando líneas regionales estratégicas que permitan, por un lado, el respeto a la cultura de las comunidades involucradas y, por otro lado, una adecuada gestión del espacio turístico en vistas a su conservación (Proyecto Red Federal de Turismo Comunitario en ámbitos rurales $(2008, \text { p. } 5)^{2}$.}

EI MINTUR apelaba al hecho de que, mediante un turismo sustentable, "las culturas originarias, su patrimonio y su territorio" serían "respetados y gestionados en vistas a su conservación" (Proyecto RATuRC, 2008) y, así, "el turismo generaría también desarrollo, favorecería el arraigo y tendría la potencialidad de reafirmar la identidad cultural de estos pueblos". Este anclaje en clave étnica -cuyo objetivo era diferenciar el territorio apelando a la identidad cultural para construir la atractividad necesaria para impulsar un proceso de valorización turístico- promovería la activación y la conservación de las particularidades culturales y étnicas de estos pueblos. Se puede afirmar, entonces, que, en este proceso reciente de valorización turística, el Estado (en sus diversas escalas) se nos presenta como un actor central al ser quien plantea el diseño y la implementación del proyecto en cuestión.

Ahora bien, en Argentina, las relaciones interétnicas entre los pueblos originarios y el Estado han sido históricamente conflictivas ${ }^{3}$. Estas se han expresado en los diseños de políticas indigenistas ejecutadas desde diversas instituciones vinculadas al control, la dominación, el exterminio, la asimilación y/o la apropiación del territorio indígena de acuerdo con el avance de la frontera agrícola, en un principio, y la asistencia o el desarrollo social, de manera más reciente, y dependiendo del período histórico a considerar y de las concepciones acerca de cómo abordar esta "problemática social". Por ello, el diseño de una política turística nacional indigenista nos señala un viraje y una novedad en cuanto a las relaciones interétnicas del Estado-nación argentino con los pueblos originarios, dado que anteriormente esta población no había sido contemplada ni considerada por estas políticas sectoriales.

De hecho, tal como señala Troncoso (2009), en contextos de actividad turística previos, muchos de estos pueblos originarios habían sido invisibilizados por el turismo pues eran percibidos como un obstáculo para el desarrollo de la actividad. De ahí que fueran ocultados por ser parte de la pobreza estructural que debe esconderse a la "mirada del turista" (Urry, 1996). Hoy, por el contrario, se los incluye, a través de su cultura, como un atractivo más del lugar, junto con el paisaje circundante (Lacko, 2008; Troncoso, 2009).

Puesto que hasta entonces las políticas indigenistas nacionales no habían sido diseñadas 
desde las políticas sectoriales del turismo, y entendiendo a la actividad turística como parte de procesos políticos, económicos y socioculturales más generales en el marco de los cuales cobra sentido, el objetivo, en este trabajo, es contextualizar dicho proceso, cuestión que consideramos clave para comprender, en primera instancia, la coyuntura que favoreció el proceso de valorización turística en el que están envueltas algunas comunidades de pueblos originarios.

Abordar este tema es relevante si se tiene en cuenta que tradicionalmente el Estado-nación argentino ha situado a los grupos indígenas en un contexto de relaciones interétnicas marcadas por la desigualdad y la subordinación, situación que los llevó a conformar unos de los sectores más empobrecidos del país (Gorosito, 2008; García \& Valverde, 2007; Lenton, 2010; Martínez, 2012). Desde una óptica muy distinta, el turismo comunitario es presentado, en el proyecto RATuRC, y según la retórica del MINTUR, como una alternativa y una promesa de desarrollo sustentable y de inclusión social para estos pueblos a través de su cultura diferencial.

Este trabajo se basa en una revisión bibliográfica especializada en la problemática a abordar. Esta se emprende desde la intersección de diversas perspectivas de las ciencias sociales, privilegiando a la antropología, pero sin dejar de tener en consideración otras disciplinas que nos ayuden a interpretar el contexto de formulación del proyecto RATuRC. También se han consultado distintos tipos de documentos, como material promocional de turismo, folletos, páginas web y diversas publicaciones emitidas por medios oficiales y otros actores.

Por otro lado, el trabajo se complementa con datos de primera mano obtenidos durante el trabajo de campo etnográfico realizado en diversos espacios en los que se ha implementado el proyecto en cuestión desde 2008 hasta 2019. Se han utilizado técnicas de observación participante y entrevistas abiertas a distintos técnicos, funcionarios, académicos y miembros de las comunidades involucrados en el proyecto.

Respecto a la estructura del texto, en la primera parte expondremos algunas consideraciones teóricas que nos permitirán reflexionar acerca del tema a discutir. En segundo lugar, describiremos el proyecto RATuRC enmarcándolo institucionalmente. En tercer lugar, exploraremos cómo esta política se relaciona con un contexto más amplio, lo que la sitúa en una coyuntura específica. Para terminar cerraremos con algunas reflexiones finales.

\section{Consideraciones teóricas}

Para poder comprender más cabalmente cómo se produce el viraje desde las políticas públicas indigenistas tradicionales hacia políticas turísticas indigenistas nacionales, cuyos destinatarios son los pueblos originarios, partiremos por una perspectiva antropológica que considera a las políticas públicas como acciones instrumentales orientadas a lidiar con problemáticas sociales existentes, así como con prácticas culturalmente situadas y producto de contextos institucionales específicos (Balbi, 2003; Balbi \& Boivin, 2008; Shore, 2010, entre otros). Tal como señala Shore (2010), para analizarlas y comprender su significación, debemos considerar los contextos socioeconómicos, políticos e históricos más amplios en los cuales están inmersas y adentrarnos en el rol social que cumplen. 
Entendemos por política indigenista a toda política de Estado que se refiera y afecte directa o indirectamente a lo que hoy denominamos pueblos originarios, independientemente de su contenido axiológico. La diferenciamos, además, de la política indígena en cuanto política de representación y estrategias de participación y/o autonomización de las organizaciones de militancia y/o colectivos de pertenencia de los pueblos originarios (Lenton, 2010).

Un aspecto clave de las políticas es la manera en que inciden en la construcción de nuevas categorías de personas, nuevas subjetividades y nuevos tipos de sujetos políticos desde las lógicas clasificatorias de la población que establecen (Shore, 2010). Desde esta perspectiva, las políticas públicas son dispositivos de poder del Estado que operan a través de discursos, prácticas y otras formas de intervención moldeando subjetividades y creando nuevos modos de ser, relacionarse y hacer (Boccara, 2007). Son, entonces, un proceso de constitución de los sujetos sociales, en el que se prioriza creando, rehaciendo y reforzando la idea de un Estado sólido y unificado (De la Maza, 2018).

Sin embargo, aquí adherimos a las perspectivas que consideran que el Estado no es una entidad unívoca y homogénea, sino que, por el contrario, se presenta como una pluralidad de agentes con visiones e intereses diferentes, y en algunos casos contradictorios (Subirats, et al., 2008), y que al diseñar e implementar las políticas operan en diversas escalas: nacional, provincial, municipal y local. Estos diferentes agentes, tal como señala De la Maza (2018), deben negociar y consensuar los conflictos y desarrollar estrategias para aplicar dichas políticas en concordancia con las demandas ciudadanas, con mayor o menor éxito. Los resultados que obtienen también son diversos e incluyen algunos inesperados o no considerados en el diseño inicial (o al menos no en forma explícita) (De la Maza, 2018).

En el caso de las políticas indigenistas en Latinoamérica, desde inicios de la década de 1980 se han observado transformaciones que van de la mano de las presiones y las demandas políticas que los pueblos originarios han ejercido desde entonces y a partir de las cuales han logrando influir y ser protagonistas en estos procesos de reconocimiento, en un marco de movilización y reivindicación política (Bengoa, 2009; Canet, 2006; Cuyul \& Davinson, 2007; Lenton, 2015, entre otros).

Por otro lado, también es necesario mencionar la particular configuración de las relaciones interétnicas, en el marco del Estado-nación argentino, en las que el proyecto RATuRC se inserta. Un factor clave en la construcción de las identidades indígenas son, precisamente, estas relaciones establecidas durante el proceso de construcción de la hegemonía del Estado-nación, el cual situó históricamente a los grupos indígenas en una estructura de desigualdad y subordinación ${ }^{4}$ (Bechis, 1992; García \& Valverde, 2007; Baines, 2012; Lustosa, 2012, 2015; Lacko, 2011; Lenton, 2005). Tal como afirma Cardoso de Oliveira (1992), las relaciones interétnicas solo pueden comprenderse de manera fructífera si se las inserta en un sistema mayor que les dé significado. Lo étnico solo puede ser entendido como lo construido en procesos sociales complejos, que deben ser necesariamente situados en un marco histórico, teniendo en cuenta las relaciones de dominación-subordinación presentes en la estructura social, los vínculos que unen, diferencian o excluyen a los individuos. 
Frente a ello cobra sentido el concepto de manipulación de la identidad étnica de Cardoso de Oliveira (1992), entendida esta como la capacidad de los grupos étnicos de jugar con identidades diversas haciendo énfasis en lo cultural para fundamentar estrategias de acción política. Este concepto permitiría dar cuenta de procesos como el de la reelaboración cultural (Cardoso de Oliveira, 1999, cit. en Baines \& Lustosa, 2015), que enfatizaría la capacidad creativa de un grupo para posicionarse, a través de la diferencia cultural, en diversas luchas por el acceso a derechos y recursos. Tal como afirman Baines \& Lustosa (2015), este proceso viene desarrollándose a lo largo de la historia. Ellos remarcan que "las identidades étnicas son siempre dinámicas, políticamente contextualizadas y, en el último siglo, en constante negociación con los Estados nacionales en cuyos contextos emergen" (p. 392).

Baines \& Lustosa (2015) retoman también el concepto de reelaboración étnica de Pacheco de Oliveira (2004) para analizar las relaciones interétnicas en el contexto de la actividad turística. Estos autores estudian a algunos pueblos originarios que han recreado sus particularidades culturales con el propósito de crear atractividad turística como una estrategia para defender sus territorios proponiendo visiones alternativas de desarrollo ante la amenaza y el avance de la frontera productiva capitalista.

Por otro lado, varios investigadores han detectado que los procesos de reelaboración étnica, etnogénesis o de reivindicación étnica articulados en torno a lo cultural encuentran mayores canales de expresión en ámbitos de desarrollo de actividad turística (Baines y Lustosa, 2015; Gruenewald, 2003; Lacko, 2008; Lustosa, 2012, 2015; Valverde \& García, 2007, entre otros).
Lacko (2008), Lustosa $(2012,2015)$ y Valverde \& García (2007) consideran que en determinados contextos interétnicos la actividad turística actúa como un catalizador o vector de la identidad étnica que se acciona para visibilizar la identidad indígena y como una forma de legitimar una negociación. Esto sucede sobre todo en procesos de reivindicaciones territoriales en los que las comunidades indígenas ven amenazada su propia supervivencia por nuevas actividades productivas de desarrollo capitalista extractivista, como la megaminería, la agroindustria, la construcción de grandes obras de infraestructura o el megaturismo, entre otras.

En este trabajo es importante destacar la instrumentalidad con que los grupos étnicos exhiben aspectos de su cultura como diacríticos particulares, como características que los diferencian por oposición a otros grupos (Gruenewald, 2003) y que tienen su correlato territorial. De esta manera demarcan las fronteras mediante las diferencias culturales. Este espacio de frontera étnica, de la diferencia cultural, es lo que se utilizaría para construir la atracción turística (Van der Berghe, 1984, cit. en Gruenewald, 2003).

Por otro lado, entendemos el turismo como una práctica social que nos permite pensar y reflexionar -a través de ella- sobre la sociedad. Este proceso, sin embargo, podría estudiarse también bidireccionalmente, dado que son las valoraciones positivas de la sociedad las que en definitiva posan su "mirada turística" (Urry, 1996) en algunos lugares para que estos devengan en atractivos turísticos. Estas valoraciones sociales positivas, que son epocales y que emergen tanto de la sociedad receptora como la de los turistas, sumadas a ciertas características inherentes a estos espacios, son las que llevan a que determi- 
nados lugares sean escogidos por actores intencionados en impulsar un proceso de construcción de atractividad turística (Bertoncello, 2009) y que, eventualmente, abrevan en un proceso de valorización turística de estos espacios. Solo aquellos lugares que conciten este interés podrán convertirse en destinos turísticos una vez creada la infraestructura correspondiente.

Así, el atractivo turístico no se define solamente a partir de una simple condición inherente al lugar, sino a partir de una asignación social que resulta de acciones que conducen a otorgarle una valoración positiva y que generen el interés por conocerlo y hacer usufructo del mismo. En efecto, tal como afirma Bertoncello (2009), los lugares en donde esto sucede devienen en lugares de destino turístico -mediante procesos específicos de valorización turística impulsados por actores sociales con diversas intencionalidades en torno a intereses disímiles-.

Finalmente, no podríamos abordar el turismo rural comunitario (TRC) sin tener en consideración los cambios que se han producido en el espacio rural a partir de la década de 1990, momento de apertura económica, en que se produjeron enormes transformaciones territoriales a partir de un cambio en el modelo agrícola, que pasó de una agricultura familiar o tradicional a un formato de agroindustria (Gras \& Hernández, 2009). Estas transformaciones, por un lado, modificaron profundamente los territorios y aumentaron de manera significativa los conflictos sociales. Ello produjo procesos de segregación y circunscripción espacial de los pequeños productores campesinos y/o las comunidades originarias. Por otro lado, vehiculizaron nuevas formas de conceptualizar y valorar el espacio rural (Castro, 2018; Velázquez, 2018; Winter \& Zusman, 2018, entre otros), que empezó a ser considerado como un ámbito más complejo que únicamente el de producción de alimentos. Se reconoció que ya no es posible hacer una separación tajante entre espacios urbanos y rurales dado que se han vuelto interdependientes (Castro, 2018).

\section{Descripción e historia del proyecto RATuRC y su entramado institucional}

A partir del año 2006, el MINTUR inició acciones para acompañar el desarrollo de la actividad turística ya iniciada autogestivamente por parte de algunas comunidades de pueblos originarios campesinos en espacios rurales. Este primer acercamiento cristalizó en el diseño del proyecto entonces llamado Red Federal de Turismo Rural Comunitario en ámbitos rurales (2008). Enmarcado en el Plan Estratégico de Turismo Sustentable (PFETS), formaba parte del Programa de Destinos y Productos para el Desarrollo Inclusivo y dependía de la Dirección Nacional de Desarrollo Turístico, donde fue ejecutado por la Dirección de Desarrollo de la Oferta.

El Instituto Nacional de Tecnología Agraria (INTA) y el Ministerio de Agricultura, Ganadería y Pesca (MAGYP), a través de la Secretaría de Agricultura Familiar (SAF), acompañó este proceso desde sus inicios brindando información y capacitación al MINTUR y a técnicos en territorio. Cabe destacar que la participación de este proyecto en el Programa de Destinos para el Desarrollo Inclusivo es coherente con lo planteado en el Plan Federal Estratégico de Turismo Sustentable (PFETS), en el cual se afirmaba que "la actividad turística permite la integración al mercado de trabajo de comunidades en zonas periféricas o disociadas de los circuitos productivos tradicionales, contri- 
buyendo a atenuar las fuertes asimetrías regionales que son características del modelo concéntrico heredado" (PFETS, 2016, p. 13).

A partir de entonces, el MINTUR, en pos de su objetivo de incentivar y acompañar la gestión de redes regionales y de la red nacional de turismo rural comunitario (TRC), desarrolló y financió una serie de acciones e instrumentos, entre los que podemos mencionar: visitas técnicas al territorio, diagnósticos, asesoramiento técnico a los emprendimientos, talleres participativos, capacitaciones, elaboración de documentos conceptuales, gestiones de recursos y formulación y diseño de proyectos. También se financió la participación de emprendedores de la RATuRC en estands de la Feria Internacional de Turismo (FIT) de Buenos Aires en forma discontinuada y se realizaron tres encuentros regionales: Norte, Litoral y Cuyo y Patagonia (estas dos últimas hasta ese momento constituían una sola región) y tres nacionales de TRC (ENTRC) (en los años 2009, 2010 y 2013) en la unidad turística de Embalse Río Tercero, Córdoba. En el I Encuentro Nacional de Emprendedores de Turismo Rural Comunitario "Un espacio en construcción 2009" se materializó y rebautizó a la red, por cuestiones de marketing, como Red Argentina de Turismo Rural Comunitario (RATuRC), como se la conoce hasta la actualidad, y se elaboró su acta de constitución.

En el II Encuentro, en el año 2010, luego de varios debates que tomaron en cuenta cómo era conceptualizado el turismo rural comunitario en otros países y en la Organización Mundial del Trabajo (OIT), este fue definido, de forma consensuada entre los participantes, como:

[...] la actividad turística autogestionada y organizada por comunidades de pueblos originarios y campesinas, en respeto a su organización tradicional, saber y cosmovisión, generando ingresos complementarios y de distribución equitativa. Esta modalidad turística es motivada por el intercambio cultural y una relación responsable entre lugareños y viajeros (Pelliza, Pérez \& Ercolani, 2012, pp. 2-3).

A partir de entonces, se integró como producto rural el proyecto "Turismo en espacios rurales de la República Argentina” (Proyecto TERRA, 2010), cuyo objetivo era, según lo expuesto en el documento, priorizar el desarrollo de una oferta inclusiva procurando una mayor equidad en la distribución de los beneficios económicos generados por la actividad turística en los espacios rurales (Pelliza et al., 2012). Este proyecto, más bien conceptual, procuró reorganizar el territorio rural definiendo y conceptualizando los diversos tipos de turismo que alí se practican asociándolos a determinados espacios rurales específicos. Entre estos se consideró el turismo rural comunitario, que se practicaría en comunidades originarias y/o campesinas en espacios rurales marginales excluidos del circuito económico nacional.

El MINTUR firmó, en 2012, el Convenio de Cooperación Interministerial para el Desarrollo del Turismo en el Espacio Rural con Inclusión Social. El objetivo del convenio, según lo puesto por escrito, era articular los instrumentos de la política pública entre los diversos sectores de la gestión para densificar el entramado institucional, drenar fondos hacia el territorio y hacer más efectiva la acción en terreno, así como regular los mecanismos de cooperación, colaboración y articulación para el mejor cumplimiento de las competencias asignadas a cada una de las jurisdicciones en lo atinente al desarrollo rural (Documento 1 Interno MINTUR, 2012). Dicho convenio se firmó entre los ministerios de Turismo (MINTUR), de Agricultura, Ganadería y Pesca 
(MAGYP) y de Desarrollo Social (MDS). Estas dos últimas instituciones, con una importante presencia territorial y con líneas de financiamiento propias que podían extenderse a la actividad turística, se comprometieron a aportar al proyecto sus recursos y articular sus instrumentos de gestión en pos del afianzamiento del proyecto RATuRC. Finalizando ese año, se sumó también el Ministerio de Trabajo, Empleo y Seguridad Social (MTEYSS), con el mismo objetivo.

En este marco, en 2012, bajo el asesoramiento técnico del MINTUR y con financiamiento del Programa de Servicios Agrícolas Provinciales (PROSAP), el Instituto Nacional de Promoción Turística (INPROTUR) y el Ministerio de Desarrollo Social (MDSS), se publicó la primera guía argentina de turismo rural comunitario en versión bilingüe, presentada después también en la Feria Internacional de Turismo (FIT) y en otros eventos de promoción. Este material turístico de excelente calidad presentaba la oferta de turismo comunitario del país dividida en cuatro regiones, que coinciden con la organización territorial del PFETS. La guía presentaba 26 emprendimientos comunitarios distribuidos ahora en cuatro regiones, con su correspondiente nombre y color turístico:

- Norte (ocre): "Colores de la Tierra", que nuclea a once organizaciones-emprendimientos.

- Litoral (verde): "Verde Paraíso", constituida por seis emprendimientos.

- Cuyo (morado-violáceo): "Tierra del Sol”, con dos experiencias comunitarias.

- Patagonia (azul turquesa): "El otro Fin del Mundo", que nuclea a siete organizaciones.

La red, en esta guía, es presentada como una entidad que promueve: "la autogestión comunitaria del turismo en pueblos originarios y/o comunidades campesinas, fortaleciendo y difundiendo la oferta de turismo rural comunitario como un nuevo producto turístico que permite captar nuevos segmentos y nichos de mercado" (RATuRC, Guía Red Argentina de Turismo Rural Comunitario, 2012, p. 15). 
Mapa 1. Localización de los diversos emprendimientos por región en el año 2012.

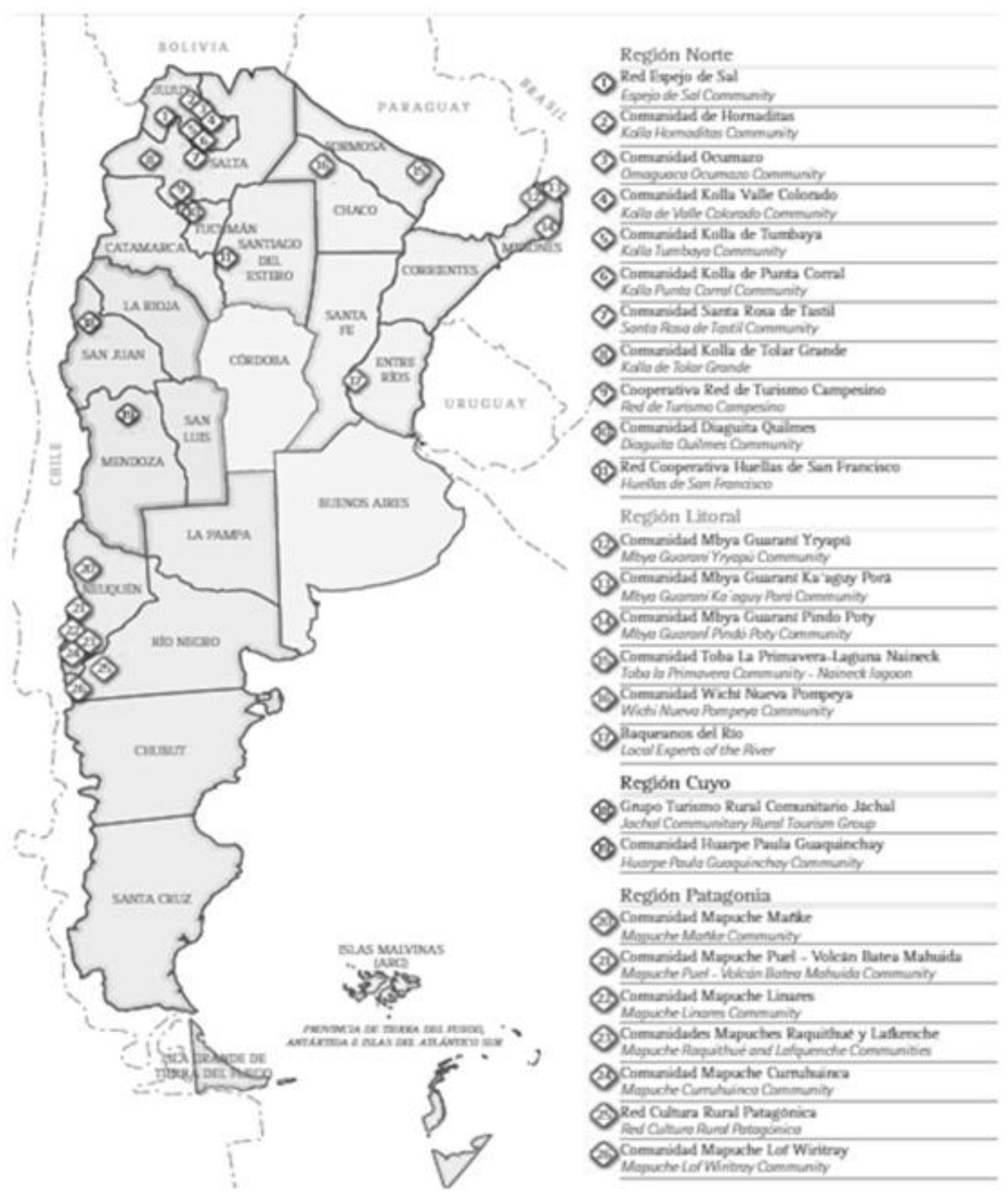

Fuente: RATuRC, Guía Red Argentina de Turismo Rural Comunitario, 2012. 
En 2013 se conformó una Comisión de Trabajo Interministerial en la que las partes definieron y programaron la ejecución concreta de actividades y proyectos que implementarían en conjunto, fijando planes, metas y los recursos que aportaría cada una (Documento 2 Interno MINTUR, 2013). Entre los trabajos realizados por la comisión, mencionamos la actualización de la base de datos, la confección de un mapa de actores de la RATuRC y el diseño de la metodología de abordaje. También se concretaron visitas a territorio para realizar relevamientos, diagnósticos, capacitaciones, planes de negocios e implementar estrategias de comercialización abordando la problemática en forma transversal e intersectorial. En 2013, el TRC contó con un importante estand independiente, cofinanciado por los cuatro ministerios, en la Feria Internacional de Turismo (FIT) en Buenos Aires.

En diciembre de 2013, gracias a la organización y el financiamiento del MINTUR y con el apoyo de los otros tres ministerios de la Comisión Interministerial, se realizó, en la Unidad Turística de Embalse Río Tercero, Córdoba, el III Encuentro de Turismo Rural Comunitario. En este encuentro nacional se hizo un fuerte hincapié en cuestiones de calidad (manipulación de alimentos, limpieza, atención al cliente, etc.) $)^{5}$. También se presentaron los Reglamentos Provinciales de TRC de Salta y Neuquén, y trece comunidades nuevas entraron en proceso de diagnóstico-evaluación, capacitación y asesoramiento técnico por parte del MINTUR.

Durante 2014, el MINTUR seleccionó a siete nuevas comunidades de las trece que presentaron su solicitud en el III Encuentro Nacional y continuó con las visitas y las capacitaciones en territorio para reforzar la oferta existente. Paralelamente, a fines de ese año, se creó la Mesa de Agroturismo, integrada por un equipo especializado del MAGYP y por integrantes del INTA, de la Unidad de Cambio Rural (UCAR) y del Programa de Cambio Rural II que dependían directamente de la Jefatura de Gabinete. Su objetivo era promover y fortalecer a los emprendimientos de pequeños y medianos productores en agroturismo, incluyendo el TRC.

En parte, la creación de esta última mesa obedeció a que, desde sus inicios, en la Comisión de Trabajo Interministerial se desataron conflictos que respondían a diferencias y prejuicios entre los funcionarios representantes de los distintos ministerios en torno a las formas de valorar, conceptualizar y significar el TRC, así como a diferencias en cuanto a los criterios de las metodologías de trabajo a implementar, que incluían también cuestiones de disputas por el protagonismo institucional y personal de algunos de los técnicos e instituciones ${ }^{6}$. A esto también habría que sumarle las tensiones lógicas de final de gestión. Esto desembocó en una crisis que llevó a la disolución paulatina de la comisión en 2015. En ese año se divorciaron las acciones en torno a la RATuRC entre los sectores de turismo y agricultura. El primero se abocó, antes de terminar con la gestión, a elaborar diversos informes sobre el trabajo realizado y a redactar un proyecto de ley de TRC de alcance nacional ${ }^{7}$. Por otro lado, la Mesa de Agroturismo gestionó doce visitas entre más de 130 emprendedores de turismo rural de todo el país con el objetivo de generar aprendizaje con el intercambio de experiencias entre pares de emprendimientos más avanzados en su gestión con otros más recientes. Esta experiencia generó un fuerte impacto valorado positivamente por quienes protagonizaron estas visitas ${ }^{8}$. 
A fines de 2015 se produjo un giro con la nueva gestión de perfil neoliberal que reestructuró completamente el organigrama del Estado, ordenó despidos masivos y gestionó nuevas incorporaciones más afines a su marco ideológico. El proyecto RATuRC a escala nacional "deja de ser un producto prioritario" para el MINTUR $^{9}$, según palabras de un funcionario, por "requerir demasiada inversión, atención en territorio y ser a muy largo plazo", por lo que quedó bajo la órbita de las políticas sectoriales del entonces Ministerio de Agroindustria, a través de la Subsecretaría de Agricultura Familiar (SSAF) de la nueva gestión y del INTA. El proyecto fue desapareciendo paulatinamente de las páginas web del MINTUR y de la FIT y su continuidad quedó relegada a las provincias, con resultados dispares según el interés de cada gestión provincial.

No obstante, los propios emprendedores de turismo rural comunitario han continuado sosteniendo, aunque con dificultades, a la RATuRC hasta la actualidad, en algunos casos de manera autogestiva o apoyados por técnicos de la SSAF y el INTA y de contadas secretarías de turismo provinciales. Fue relevante, en ese proceso, el rol de algunos liderazgos de técnicos de la SSAF y el INTA, así como de emprendedores y líderes de los pueblos originarios. Algunas comunidades y técnicos continuaron sosteniendo a la red de forma local y lograron realizar un IV Encuentro Nacional de TRC en Pozo del Arbolito, Santiago del Estero, en 2017, con escasa financiación estatal y con una participación, en muchos casos autofinan- ciada, de más de 120 asistentes, entre emprendedores, técnicos y funcionarios del INTA y la SSAF y organizaciones campesinas locales que prestaron su apoyo articulando acciones y brindando el servicio de comidas. Este encuentro puso en evidencia que la red, a pesar de no estar muy sostenida ni financiada ya por políticas públicas nacionales, había comenzado a generar una institucionalidad y vida propias. El encuentro logró visibilizar las acciones aisladas que se estaban llevando a cabo local y provincialmente, lo que permitió repensar de nuevo un proyecto que superara la escala provincial, aunque fuese autogestionado o con escasa participación del Estado nacional.

En 2019, a diez años de iniciarse la red, se realizará un $V$ Encuentro Nacional en la ciudad de San Carlos de Bariloche. Esta vez el financiamiento será aportado, en parte, por la provincia de Río Negro y -luego de arduas negociaciones iniciadas en 2017 y apelando a contactos personales de los técnicos líderes del proyecto con funcionarios nacionales- por la actual Secretaría de Turismo de la Nación. En la planificación del encuentro participan diversos técnicos y comunidades fundadoras de la RATuRC, entre los que figura un técnico de la SSAF de la provincia de Salta y dos técnicas de Río Negro, que fueron despedidas en el transcurso de la actual gestión y que ahora trabajan como voluntarias ad honorem ${ }^{10}$. Las comunidades mapuche Wiritray y Villa Llanquín, de la red provincial Cultura Rural Patagónica, que organiza junto a la Fundación Buenavida ${ }^{11}$, serán las anfitrionas del futuro encuentro ${ }^{12}$. 


\section{Reconstrucción del contexto de surgimiento del proyecto RATuRC como política pública nacional}

Contexto general de la región, organismos internacionales y transformaciones en las formas de concebir las políticas públicas en Argentina (2003-2015)

En varios países de la región, durante la década de 1990, con la crisis del Estado de Bienestar y la instalación de un paradigma basado en el neoliberalismo, se impuso la lógica del mercado por sobre la intervención estatal. El Estado, en ese contexto, se tornó funcional a los intereses del mercado, lo que repercutió en una mayor situación de fragmentación y exclusión social y en el incremento de la pobreza y la desigualdad en Latinoamérica (Arroyo, 2005). Esta situación de pauperización se presentó de forma más agravada en los espacios rurales ocupados por pequeños y medianos productores tradicionales, incluyendo a comunidades campesinas y/o de pueblos originarios, cuya producción se destinaba, sobre todo, a la subsistencia con escasos excedentes que se comercializaban localmente.

En este contexto, el de un modelo al que algunos autores denominaron "neoextractivismo" (Gudynas, 2010), estos productores vieron amenazada su subsistencia ante el avance de la frontera productiva facilitada por nuevas tecnologías de extracción y la apertura del mercado al capital transnacional, propiciada por las políticas neoliberales de los gobiernos. Esta forma de producción, que basa su patrón de acumulación en la sobreexplotación de los recursos naturales, en gran parte no renovables, fue expandiendo las fronteras extractivas hacia lugares antes supuestamente improduc- tivos (muchos ocupados por las comunidades que aquí nos interesan), lo que primarizó la economía. Casos paradigmáticos de estas actividades en Latinoamérica son la megaminería, la explotación de hidrocarburos, los agronegocios y los megaempredimientos turísticos. A todo esto se suman grandes obras de infraestructura para sostener este modelo, como centrales y represas hidroeléctricas, obras viales, puertos, etc., que también impactan sobre los territorios de los pequeños productores.

Esto derivó en una amenaza real para las comunidades rurales -tanto por la ocupación y la usurpación de sus territorios como por la apropiación de los recursos naturales necesarios para su subsistencia-, las cuales cada vez más empezaron a ser expulsadas, arrinconadas y/o circunscritas espacialmente (Baines, 2012; Baines \& Lustosa, 2015; Lacko, 2019; Lenton, 2005; Lustosa, 2012, 2015). Estas comunidades respondieron mediante diversas estrategias, que incluyeron tanto la acción política como las luchas por reclamos de demandas históricas (tierra, acceso a recursos y derechos políticos, culturales y socioeconómicos). Este accionar, llevado a cabo por distintos movimientos y organizaciones indígenas surgidos a partir de la década de 1980, se incrementó con el retorno a la democracia de gran parte de los países de la región y dio inicio a lo que Bengoa (2009) denominó "segunda etapa de emergencia étnica".

Este período es caracterizado como una nueva fase de descolonización y un momento en el que los pueblos indígenas iniciaron una búsqueda de apropiación de los instrumentos y las instituciones del Estado y no se limitaron a retraerse en sus comunidades originarias en una suerte de repliegue o "autoapartheid" (Bengoa, 
2009). Como respuesta a esta situación y ante el aumento de la conflictividad social, la tendencia preponderante en foros, documentos y organismos internacionales en la década siguiente se centró en denunciar la situación de explotación y subordinación de estos sectores más vulnerables (Bolados, 2009).

Ante este panorama, a inicios del siglo XXI y con el retorno de la democracia en la mayoría de los países latinoamericanos, algunos organismos internacionales diseñaron instrumentos de financiamiento y lineamientos teórico-metodológicos de desarrollo local para estos espacios rurales pauperizados que tenían en cuenta el componente cultural indígena campesino como alternativas para paliar esa situación. Entre estas recetas, la Organización Internacional del Trabajo (OIT), la Organización Mundial de Turismo (OMT) y, en menor medida, la Organización de las Naciones Unidas para la Alimentación y la Agricultura (FAO), promovieron activamente el turismo comunitario como una "alternativa de desarrollo local sustentable, complementaria a la economía tradicional y respetuosa de la diversidad cultural". Estas acciones de diversas agencias internacionales fueron marcando la agenda de los países de la región, y la de Argentina en particular, influyendo mediante el asesoramiento experto también en las políticas públicas nacionales en relación con los pueblos originarios y las de turismo.

La OIT realizó, desde el año 2002, numerosos encuentros nacionales, binacionales y regionales de turismo comunitario en el que se brindaron capacitaciones que incluían discusiones conceptuales y acerca de las normativas legales que enmarcarían a dicha actividad. De esta forma, dicho organismo se constituyó en uno de los principales difusores de esta nueva práctica turística y en el responsable de la capacitación del "saber experto local" al instruir a los formadores locales, líderes comunales y cuerpos técnicos gubernamentales en la materia en Latinoamérica. A partir de estas intervenciones se fueron creando diversas redes de turismo comunitario que abarcan varias escalas. Algunas de ellas son nacionales y están afectas a la intervención del Estado, con mayor o menor intensidad, mediante políticas públicas sectoriales de turismo (como en los casos de Bolivia y Ecuador). Otras, de menor escala, son apoyadas, muchas veces, por gobiernos locales, la academia, ONG y otras agencias, nacionales o internacionales, que operan a nivel local o regional.

En 2007, un funcionario del MINTUR argentino, perteneciente al área de desarrollo de la oferta, fue a capacitarse a Quito en un curso-taller para "formar capacitadores en turismo comunitario" organizado por la OIT y el programa Sustainable Tourism-Eliminating Poverty (ST-EP) para la región andina y América del Sur de la OMT, enmarcado en el programa REDTUR. En 2008, el MINTUR publicó su primer proyecto escrito: Red Federal de Turismo Comunitario en ámbitos rurales, instalando con él esta nueva práctica turística en Argentina. Vale aclarar que la aparición de este documento se dio en el marco de una nueva forma de conceptualizar la política pública iniciada en 2003 bajo el gobierno de Néstor Kirchner.

Precisamente, centrándonos ya en Argentina y antes de ocuparnos de las políticas sectoriales que nos interesan, es menester ahondar un poco más en este viraje en las formas de conceptualizar las políticas públicas nacionales que se lleva a cabo en la gestión Kirchner-Fernández 2003-2015 (en consonancia con 
cambios similares acaecidos en otros países de la región). Con este enfoque se proponía corregir los efectos de pauperización generados por las medidas neoliberales implantadas por los gobiernos anteriores (De Mattos, 1984; Massiris, 2008; Moncayo, 2001). El nuevo modelo priorizó la intervención del Estado en la planificación de las políticas públicas estratégicas basadas en el ordenamiento territorial ${ }^{13}$. Estos lineamientos se cristalizaron en 2004 en la Política y Estrategia Nacional de Desarrollo y Ordenamiento Territorial (PENDOT, 2004), diseñada por el Ministerio de Planificación Federal, Inversión Pública y Servicios. En ella se reconoce la necesidad de construir un nuevo modelo de desarrollo poniendo el foco en el territorio y se plantea, entre los instrumentos para lograr el modelo territorial deseado, el Plan Estratégico Territorial ${ }^{14}$ (PET) y la Ley Nacional de Desarrollo y Ordenamientos del Territorio, ambos presentados también en 2004, con el objetivo de coordinar y armonizar las políticas sectoriales y territoriales en pos de un objetivo común.

\section{Acerca de las políticas turísticas nacionales} (Argentina 2003-2015)

En Argentina, el diseño de las políticas turísticas no ha sido ajeno a los lineamientos políticos generales descritos en el apartado anterior. La primera gestión de Kirchner (2003-2007) tuvo que enfrentarse a los profundos efectos de la crisis económica, política y social acaecida en 2001, resultado de las políticas neoliberales de la década anterior. La devaluación de 2003 y el retorno a la paz social favorecieron el turismo receptivo atraído por la diferencia del tipo cambiario en un contexto en el que el turismo internacional estaba en una etapa de pleno crecimiento. Por otro lado, el restablecimiento de la estabilidad política y el alza del costo de los viajes al exterior propició la circulación interna de ciudadanos cuyo poder adquisitivo les permitía disfrutar las diversas atracciones turísticas que ofrecía el país. Este hecho no fue desatendido por el gobierno: desde el año 2003 el turismo fue declarado como una "actividad prioritaria estratégica dentro de las políticas de Estado" y un "motor de la reactivación económica como generador de divisas" en la Ley Nacional de Turismo 25.997.

Esta ley dispuso, a su vez, que las políticas nacionales de la actividad turística debían fijarse a través de un plan federal, que se desprendería del Plan Estratégico General (PET). El Plan Federal Estratégico de Turismo Sustentable (PFETS) fue acordado en 2004 y firmado por el Consejo Federal de Inversiones (CFI), la Administración de Parques Nacionales (APN) y la Cámara Federal de Turismo (CFT) como socio estratégico activo. En 2009, la Secretaría de Turismo de la Nación es elevada a grado de ministerio, enfatizando con ello la importancia que esa gestión le asignaba a esta actividad.

En este contexto, el gobierno nacional apostó a la marca país y a las submarcas regionales, segmentando el mercado turístico de acuerdo con las demandas y las normas de competitividad internacionales. Es entonces que la Argentina lanza un "mapa turístico" regionalizado (NOA, Litoral, Córdoba, Cuyo, Patagonia, Buenos Aires) junto con un conjunto de productos, como: turismo activo (ecoturismo, turismo aventura, turismo rural y turismo joven); turismo cultural (turismo idiomático -que recién aparecerá en 2008-y turismo religioso); turismo de deporte (esquí, golf, pesca); turismo de 
interés especial (congresos e incentivos, rutas del vino, trenes turísticos) y el turismo de salud. De esta manera se contribuyó a la consolidación paulatina de una estrategia de búsqueda y desarrollo de nuevos atractivos para satisfacer una demanda más variada a lo largo de todo el territorio nacional haciendo énfasis en el "desarrollo turístico local" y en "promocionar esta diversidad", ya sea natural o cultural, presente en los territorios.

En este marco cobra sentido apoyar e incentivar, mediante políticas específicas que van diferenciando el territorio desde el marco de la cultura (y eventualmente del paisaje rural circundante), a algunas comunidades de pueblos originarios y/o campesinas que ya habían comenzado a brindar algún tipo de servicio turístico en forma autogestionada. Desde estas visiones de la política turística, uno de los objetivos era crear un producto apto para ser ofrecido al mercado internacional ávido de nuevas experiencias, diversificando así aún más la oferta nacional. Este proceso de valorización turístico era sostenido por el discurso estatal, que aseveraba que esta nueva actividad devendría en el desarrollo inclusivo de estos espacios desintegrados de la economía nacional.

Transformaciones en las prácticas turísticas en el siglo XXI

Al finalizar el siglo pasado, se comienza a cuestionar con fuerza el turismo de masa desde las ciencias sociales y toma un fuerte impulso el turismo cultural y/o patrimonial. Organismos internacionales como la OMT se convierten en impulsores de estas miradas basándose en una serie de supuestos que afirman que esta modalidad de turismo y de turista (el turista cultural o patrimonial) no traería aparejada los problemas económicos y sociales que se visibilizaban en varios destinos de turismo masivo. Este turismo, denominado posturismo o alternativo, iniciado en las décadas de 1980 y 1990 (Molina, 2000), se caracterizaría por la desconcentración temporal (flexibilización del mercado laboral que permite la multiplicación de los períodos vacacionales de los turistas) y espacial (incorporación de nuevos destinos y revitalización de los ya existentes); por el surgimiento de nuevos actores vinculados a la oferta turística (Marchena, s.f.) y por el impacto producido por las innovaciones tecnológicas que permiten una mayor disponibilidad de información para los viajeros.

Como consecuencia de lo mencionado podemos observar la emergencia de una cantidad de empresas vinculadas al turismo que combinan sus esfuerzos para atender una demanda turística cada vez más delimitada y, por ende, que confeccionan productos turísticos cada vez más exclusivos y dirigidos a mercados específicos (Marchena, s.f.; Urry, 1996). Con ello se definen nuevos segmentos para atender a un consumidor muy bien informado y poder competir en el mercado global.

Las características del posturismo reflejan, de este modo, las transformaciones económicas y sociales marcadas por una progresiva especialización de la producción destinada a un consumidor que demandaría ciertas especificidades en los productos consumidos (Meethan, 2001). En este marco, surgen nuevas modalidades turísticas que acompañan a las tradicionales de sol y playa estandarizadas y que diversos actores adecúan a las nuevas necesidades de estos tiempos (turismo aventura, turismo rural, turismo gastronómico, etnoturismo, etc.). Estas 
nuevas formas de viajar, como señalan Cáceres, Troncoso \& Vanevic (2013), expresan otra forma de valorar y consumir espacios con características naturales o culturales dignas de admiración (Urry, 1996), entre ellas aquellas consideradas en vías de extinción (Nouzeilles, 2002).

Por otro lado, para Castro (2018), Velázquez (2018) y Winter \& Zusman (2018), entre otros, este proceso acelerado de creación de nuevos productos, destinos y tipos de turismo para mercados específicos no responde solamente a cambios tecnológicos, a la mayor disponibilidad de información por parte de los viajeros o a cambios en los períodos vacacionales, como suele señalarse. Estos autores afirman que este proceso es el resultado de la mercantilización mundial de lugares. Para Velázquez (2018), cada lugar compite por captar la mayor porción del gasto turístico que le sea posible, tratando de obtener lo que Harvey (2007, cit. en Velázquez, 2018) denomina "rentas de monopolio" a través de la aplicación constante de criterios de especialidad, singularidad, originalidad y autenticidad. En este contexto es que se ponen en valor las características naturales, ecológicas, históricas y culturales de los lugares, y nuevos espacios pasan a ser valorizados, como los rurales periféricos, cuyo territorio se distingue por el componente cultural campesino-indígena $y$, eventualmente, por su paisaje circundante (Velázquez, 2018).

Políticas indigenistas y relaciones interétnicas entre pueblos originarios y el Estado-nación argentino

En cuanto a los cambios políticos que posibilitaron el ingreso en la agenda de políticas públicas de turismo a los pueblos originarios en ámbitos rurales, este no hubiera sido posible sin las transformaciones en las relaciones interétnicas entre estos y el Estado y la sociedad en general.

En Argentina, desde el inicio de la democracia en 1983 y hasta los años noventa y como respuesta a las presiones ejercidas por algunas agencias internacionales y a las luchas, las demandas y los reclamos de los movimientos y las organizaciones indígenas y/o campesinas, las problemáticas de esta población y su vinculación con la pobreza rural alcanzaron mayor visibilidad. El ímpetu democratizador que caracterizó a estos años implicó tanto la presión social para la reinstauración de derechos humanos como la definición de nuevos sujetos de derecho (Briones et al., 2000, cit. en Lenton, 2010). De este modo, se comenzó a instalar “la aceptación de una nueva 'generación' de derechos humanos aplicables a aquellos sujetos colectivos cuya excepcionalidad se define como preexistencia al Estado" (Lenton, 2010, pp. 72-74). Esto conllevó la necesidad de redefinir, por parte del Estado, la relación que mantenía con los pueblos originarios.

Entre los instrumentos estatales diseñados o firmados para tratar esta problemática mencionamos, en primer término, la reforma constitucional de 1994; la Ley Nacional 23.302 sobre Política Indígena y Apoyo a las Comunidades Aborígenes de 1989; el Reglamento № 155/89 asociado, en el que se crea el Instituto Nacional de Asuntos Indígenas (INAI) como organismo competente y dependiente del Ministerio de Desarrollo Social, y la ratificación del Convenio 169 de la OIT sobre Pueblos Indígenas y Tribales en Países Independientes acordada en 2001. Este convenio debía generar las condiciones para una participación efectiva de los pueblos originarios, enfatizando el derecho al territorio y 
la cultura y presionando para la instalación de la problemática indígena tanto en la agenda internacional como en la nacional (Lenton, 2015; Lacko, 2011; Martínez, 2012). Por otro lado, también se materializaron diferentes instrumentos legales elaborados por varias provincias que reconocieron derechos específicos a los pueblos originarios.

Sin embargo, y a pesar de crearse este espacio de reconocimiento de derechos, este proceso se vio atravesado, en la misma década de 1990, por la irrupción del neoliberalismo, cuyas políticas indigenistas se caracterizaron por una tendencia neoasistencialista, particularizadora, privatizadora y antiestatal (Lenton \& Lorenzetti, 2005). El Estado, en este contexto, convirtió a la política indigenista en política indigenista de aporte privado. Para que esto sucediese, se requirió la difusión y la aceptación previa de un paradigma multiculturalista que, en los años de flexibilización económica y social de esa década, predominó en el ámbito privado y en algunas agencias estatales. En este escenario aparece lo que varios autores denominaron el neoindigenismo (Briones \& Carrasco, 2004; Lenton \& Lorenzetti, 2005).

Ahora bien, durante la administración Kirchner-Fernández (2003-2017), luego del estallido social y económico de 2001, el Estado retomó protagonismo en la planificación de las políticas públicas, como ya lo anticipamos. Así, comenzó a reforzar el marco institucional y legal para rediseñar las políticas indigenistas con el objetivo de atender la histórica situación de vulnerabilidad de esta población, sobre todo en lo referente a la problemática de la tierra y el acceso a los recursos (Gorosito, 2008; Martínez, 2012). Durante la gestión de Kirchner se promulga la Ley 26.160 de Emergencia de
Tierras que suspende los desalojos de tierras ocupadas; se dictamina la creación de un relevamiento territorial jurídico y catastral de todo el país y se reafirma al Instituto Nacional de Asuntos Indígenas (INAI) como ente competente para crear programas de implementación de políticas indigenistas (Decreto № 1122/07). Esto cristaliza, luego, en el Programa Nacional de Relevamiento Territorial de Comunidades Indígenas (RETECI) (Resolución INAI №587/07); el Programa de Fortalecimiento Comunitario y Acceso a la Justicia (Resolución 235/04), y la creación del Registro Nacional de Comunidades Indígenas (RENACI) (Resolución № $4811 / 96 a)^{15}$.

La otra cuestión coyuntural que no es menor, y que instaló este renovado interés por la problemática de esta población, es la de las luchas llevadas a cabo por diversas organizaciones políticas y movimientos indígenas y campesinos, iniciadas tímidamente en la década de 1960 (Lenton, 2015) y que se fueron incrementando a partir del inicio de la democracia. Su accionar puso de relieve la cuestión indígena en la agenda de derechos humanos en el país y en la región (Bengoa, 2009; Canet, 2006; Lenton, 2015). Tal como apunta Briones (2005), esta nueva juridización del derecho indígena y de la diferencia cultural instaló otras condiciones para la constitución de nuevas representaciones y prácticas referidas a la cuestión indígena.

\section{Políticas sectoriales agrícolas y valorización} turística del espacio rural

No podemos dejar de mencionar el cambio de enfoque -en coherencia con el PET-que se produjo también en las políticas públicas sectoriales agrícolas. Las nuevas visiones 
sostienen que no existiría "una sola agricultura" sino una heterogeneidad de formas y actores agrícolas, diferenciando y dándole importancia a la "agricultura familiar", la de los pequeños productores campesinos, y entre estos a los pueblos originarios. Según esta perspectiva, se necesitaría un apoyo diferencial por parte del Estado debido a la existencia de alarmantes situaciones de desigualdad en el espacio rural y de pobreza estructural y marginalidad en ciertas comunidades rurales (entre ellas algunas comunidades indígenas).

La atención de esta problemática ha adquirido una singular importancia a partir del diseño del Plan Estratégico Agroalimentario y Agroindustrial Participativo y Federal 2020 del Ministerio de Agricultura, Ganadería y Pesca (Lattuada, Marques \& Neme, 2012) y la creación de la Secretaría de Agricultura Familiar (SAF) en el contexto de la elevación de la Secretaría de Agricultura, Ganadería y Pesca a grado de Ministerio. Bajo ese paraguas se elaboraron diversos planes y proyectos para atender la problemática de la pobreza rural, que se sustentaba en el nuevo paradigma de desarrollo rural, "el desarrollo territorial rural", el cual entiende que "el medio rural excede lo estrictamente agrícola y aun lo agropecuario para involucrar todas las actividades económicas generadoras de ingreso que las personas asentadas en el medio rural pudieran llevar adelante, incluyendo al turismo, otros servicios, las artesanías y la agroindustria" (Lattuada et al., 2012).

Esta perspectiva del desarrollo territorial rural y de la agricultura familiar es fundamental para comprender la articulación entre las políticas sectoriales de turismo y agricultura, dado que fueron los técnicos en terreno, ligados sobre todo al Instituto Nacional de Tecnología Agraria
(INTA) y a la SAF, los que identificaron y propiciaron (tomando como modelo experiencias de turismo rural de la Unión Europea y latinoamericanas) el turismo rural y el TRC como una actividad productiva complementaria a la agricultura. Posteriormente, las políticas públicas del sector turismo, en el diseño de los proyectos de Productos en el Espacio Rural para la Inclusión Social, se basaron en las conceptualizaciones acerca del territorio del modelo de desarrollo territorial rural y de la modalidad de gestión (participativa, en forma de talleres en los que se reconoce el "saber local", de "abajo hacia arriba", con focalización en el nivel "micro", etc.) elaboradas y ya experimentadas por las políticas públicas del sector agrícola.

Estas políticas han sido diseñadas en un contexto en el que el espacio rural ha sufrido, en los últimos treinta años, transformaciones sin precedentes. Entre estas

[...] se destacan la reestructuración agraria y la expansión del agronegocio, la promoción de las valorizaciones recreativo-turísticas y patrimoniales del campo, los movimientos de agricultura familiar y la soberanía alimentaria y, en articulación con ellos, las disputas en torno a las tierras, ambientes y territorios y los planteos con respecto a las políticas de desarrollo rural (Castro, 2018, p. 19).

El turismo rural, junto al uso residencial del campo, son algunas de las actividades que más han incidido en las modificaciones no rurales que acontecieron en ese ámbito. Este, incluyendo el TRC, atrae a nuevos agentes económicos y grupos sociales, y les asigna otras funciones transformando el espacio rural en una nueva mercancía. Con ello va adquiriendo una fisonomía distinta, pasa de ser un espacio a ser consumido por los turistas. 
Ahora bien, para que el espacio suscite necesidad de ser consumido por el turismo tienen que haberse producido también algunas transformaciones en su valoración social positiva. Castro (2018) identifica, en la actualidad (desde la geografía simbólica), cómo ciertas ideas del pasado se reactualizan y operan hoy con nuevos sentidos en la mercantilización y la valorización de los espacios rurales también para el turismo y como remedio a los males metropolitanos (polución, vertiginosidad, hacinamiento, etc.).

Entre estas nociones se privilegia la idea de "el campo como refugio" con reminiscencias del ideario romántico de fines del siglo XVIII y XIX -que valorizaba moral y espiritualmente a los entornos naturales rurales escasamente artificializados- o los movimientos utópicos del neorruralismo de la década de 1960 influenciados por el Mayo francés, que proponían un "retorno al campo" en donde se priorizaba e idealizaba la vida comunitaria. Finalmente rescatamos la noción de "idilio rural" de Bell (2006), interpretada como un eterno deseo de "retorno a la naturaleza", que en diferentes momentos -con mayor o menor intensidad y con distintos sentidos y orientaciones- se apoderó de la sociedad industrializada iniciado el siglo XVIII (Castro, 2018; Velázquez, 2018). Estas renovadas ideas acerca del campo promueven valorizaciones del espacio rural como espacio turístico dándole sentido a una práctica como la del TRC, que se sustenta en estas nociones, muy presentes en los folletos turísticos oficiales, más allá de los sentidos que el TRC tiene para los diversos actores que participan en la RATuRC y que también son disputados.

\section{Reflexiones finales}

Para finalizar este artículo queremos destacar la importancia de la recuperación del contexto y de la historización del diseño y la implementación de una política pública como práctica social históricamente situada. El caso RATuRC ha sido un proyecto menor en la cartera de los ministerios que han intervenido. Sin embargo, cuando se realiza la tarea de reconstrucción de su contexto de surgimiento, lo primero que se vislumbra es su complejidad. Es decir, la gran cantidad de factores sociales, políticos, económicos y culturales que inciden en la formulación y luego la implementación del mismo.

Hemos identificado y descrito algunas cuestiones que han abrevado para que este proyecto se materializara en 2008: la influencia de los organismos internacionales en la agenda política turística e indigenista de Argentina; la situación de vulnerabilidad y circunscripción espacial de los pueblos originarios en los espacios rurales propia del modelo de desarrollo neoextractivista, y el contexto de luchas de movimientos y organizaciones indígenas enmarcados en reclamos por derechos a la tierra, la cultura y la participación política, material y social. Mencionamos también la particular configuración de las relaciones interétnicas entre los pueblos originarios y el Estado, las transformaciones en la concepción de las políticas públicas al cambiar el modelo de gestión y el rol que asume el Estado. Por otro lado, también señalamos transformaciones productivas y sociales de diversa índole, como las nuevas formas de consumo turístico, los sentidos y las valoraciones sociales que se asignan hoy al "campo"16 y la mercantilización de los espacios y las culturas rurales e indígenas, y los relacionamos con la práctica turística. 
Sin duda, la aparición de una política destinada a los pueblos originarios desde el MINTUR es una novedad e implica un momento de ruptura en cuanto a los destinatarios a quienes está dirigida esa política sectorial. Podríamos afirmar que se trata de una política turística indigenista, que, si bien es focalizada -dado que solo atañe a algunas comunidades originarias seleccionadas por el proyecto y que ya habían comenzado a brindar algún tipo de servicio turístico-, no deja de afectar directa o indirectamente a los pueblos originarios.

Los afecta directamente porque, como todo dispositivo de poder del Estado, moldea subjetividades y crea, por lo tanto, nuevos modos de ser, relacionarse y hacer (Boccara, 2007). Tal como señala Shore (2010), estos conforman una nueva categoría de persona: "el emprendedor de TRC de pueblos originarios". El surgimiento de nuevos actores por parte de este proyecto es observable en la redacción de los documentos y en las prácticas estatales propiciadas por funcionarios del MINTUR y, en especial, durante los encuentros nacionales de TRC I, II y III realizados en Córdoba, que resultaron instrumentos privilegiados para introducir estas nuevas formas de ser (cómo debe ser un emprendedor de TRC), de relacionarse (en comunidad, asociativamente, en forma participativa, horizontal, utilizando mecanismos como las asambleas, etc.) y de hacer (reparto equitativo de los beneficios del turismo, normas de calidad para brindar servicios, etc.).

Por otro lado, esta política indigenista afecta indirectamente al resto de las comunidades no pertenecientes a la red y a personas que son parte de las comunidades adscritas a la RATuRC pero que no participan brindando servicios turísticos en la localidad. Estas últimas ven afectadas sus vidas por el ingreso de turistas en su comunidad o en las vecinas. A su vez, para ingresar a la red, la comunidad interesada necesita ser presentada por otra comunidad miembro o bien que la propia comunidad solicite al MINTUR su ingreso para que se inicie el proceso de evaluación y diagnóstico.

Una futura línea de investigación podría ahondar en los efectos que produce en comunidades que no participan del proyecto el hecho de observar cómo en otras se generan beneficios económicos por el turismo u otros, así como la utilización de los discursos turísticos para defender tanto los territorios como los recursos ante nuevos avances de la frontera capitalista en comunidades vecinas. También pueden darse diversas reacciones como resultado de otros efectos indeseados asociados también a la actividad turística, como el incremento de la diferenciación socioeconómica entre unidades domésticas de una misma comunidad, lo que propicia una mayor desigualdad; la aparición de consumos problemáticos; la transformación en las relaciones sociales, de género y generacionales, y problemas ambientales y territoriales, entre otros.

El Estado intervino activamente en el proceso de turistificación que se está llevando a cabo en algunas comunidades de pueblos originarios al diseñar e implementar el proyecto RATuRC. Lo hizo intersectorialmente y desde distintas escalas (nacional, provincial y municipal), y en ese proceso fueron particularmente influyentes los técnicos territoriales que actuaron de mediadores, sobre todo en los momentos de interfaz (Long, 2001, cit. en De la Maza, 2018) y durante las capacitaciones y los encuentros nacionales como parte del "saber experto" legitimado desde el Estado. 
Es menester, además, mediante una perspectiva comparativa, investigar los diversos casos de comunidades que ingresaron a la red. Las políticas nacionales de TRC homogeneizaban, desde los discursos inscritos en los documentos, a todas las comunidades en el territorio argentino cuando lo que las caracteriza es la diversidad (cultural, política y socioeconómica). Fueron los técnicos quienes tuvieron que adaptar las directivas a cada contexto y cultura cuando las "bajaban" al territorio. Los resultados que obtuvieron fueron diversos, incluso algunos inesperados. Estos procesos, que dependen de cada contexto, esperan aún ser investigados.

Por otro lado, es sumamente interesante continuar, a futuro, el análisis del derrotero que va tomando la red con la creación de la Fundación Buenavida por parte de algunos técnicos que trabajaban en territorio. La creación de esta organización del tercer sector responde a una estrategia por parte de algunos de estos ante la incertidumbre que se genera en torno a la continuidad de la red cuando se suceden los cambios de gestión política y como una forma de salvaguardar y defender su fuente laboral, que está continuamente amenazada por la precariedad de sus contratos laborales con el Estado. Así, podrían en el futuro no pertenecer al equipo del Estado a partir de la creación de esta fundación y abrir un nuevo espacio de acción, al no ser ellos parte de los pueblos originarios, que habrá que seguir con atención, dado que podrían ser las simientes de una nueva institucionalidad de características novedosas.

Entendemos que se trata de una política indigenista cuyos efectos todavía no podemos predecir y que, a pesar de su desaparición de la agenda turística nacional con el inicio de la gestión de Macri (2015-2019) (y su reapari- ción reciente en el período preelectoral con el apoyo financiero al $\mathrm{V}$ Encuentro Nacional de TRC 2019), mantiene una continuidad dispar en algunos territorios, impulsada por las secretarías de turismo de distintas provincias, por líderes y emprendedores indígenas y por la actual Subsecretaría de Agricultura Familiar. Esta última, a pesar de haber sufrido despidos masivos, continúa teniendo a algunos técnicos claves en territorio para que la red pueda subsistir, aunque con mucho esfuerzo.

A lo largo del texto hemos reflexionado acerca de las relaciones interétnicas entre el Estado argentino y los pueblos originarios. Shore (2010) considera que la antropología de la política pública permite abordar algunas preguntas, como las relativas a la transformación del Estado moderno, la emergencia de nuevos métodos de gobierno y la articulación de relaciones distintas de poder, es decir, de nuevas formas de gubernamentalidad. Mencionamos que el Estado, en la década de 1990, impuso un nuevo modelo de políticas indigenistas, diferenciándose de las tradicionales (ligadas a la seguridad y la asistencia social tutelar), al que Briones \& Carrasco (2004) denominaron "neoindigenismo" de Estado. Esta forma de gubernamentalidad ha sido caracterizada por la tercerización del asistencialismo. Es decir, que el asistencialismo, que antes surgía de dependencias estatales y estructuras gubernamentales para atender la situación de los pueblos originarios (y otros actores sociales vulnerables), se redireccionó hacia organismos internacionales y/o multilaterales de crédito, ONG y otras organizaciones privadas o de la sociedad civil. El Estado, en este contexto, dejaba de tener responsabilidad por los proyectos generados por estos o por sus impactos o consecuencias, incluso las financieras (Castro, 2008). 
Ahora bien, en el período del caso estudiado, las políticas turística indigenistas propiciadas desde el Estado se centraron en la valorización de la cultura indígena y, en menor medida, en las reivindicaciones de derechos políticos o materiales. Será de sumo interés continuar investigando poniendo el foco en las formas de gubernamentalidad particulares que se han creado desde el Estado en el período de la gestión 2003-2015 a partir de este proyecto de TRC. En él, el Estado ha intervenido fuertemente en el territorio, pero con el objetivo de crear agentes responsables de construir su propio desarrollo, apelando, preservando y acentuando, en sus discursos y prácticas, el derecho a la cultura diferencial indígena.

Hale (2004) se hace interesantes preguntas acerca de estas políticas, hijas aún del multiculturalismo y basadas en el reconocimiento de derechos culturales que han surgido en Latinoamérica en el contexto del neoliberalismo. Para él, durante estas últimas décadas, los Estados latinoamericanos han establecido nuevas formas de gobernar. Hale se pregunta si no estamos frente a un nuevo tipo de racismo en el que el reconocimiento de derechos (sobre todo culturales) por parte del Estado se da solo para un sector pequeño de la población originaria ("los indios permitidos") mientras que el resto de esta población queda subsumida en la marginación por parte de las políticas focalizadas (estos constituirían "los indios no autorizados", por ser combativos o problemáticos para los intereses del Estado). Así, para este autor, desde el Estado se reconocerían los derechos culturales "autorizados" mientras se niega o posterga el acceso a derechos económicos y políticos que son mucho más conflictivos.

Nos preguntamos, entonces, junto a Hale, si lo que se está jugando "no es simplemente una lucha de derechos colectivos e individuales, ni una dicotomía entre lo cultural y lo material, sino un acondicionamiento mucho más sutil: un esfuerzo de fijar límites preestablecidos para estos espacios de participación política indígena" (2004, pp. 6-7). No resultaría sospechoso pensar que un Estado, luego de políticas indigenistas que intentaron, primero, exterminar y, después, asimilar a la población indígena, relegue a esta a una actividad como el turismo, que para llevarse a cabo necesariamente requiere de territorios de baja conflictividad social, inhibiendo de este modo la intensificación de los reclamos históricos, sobre todo los atinentes a la participación política, el reconocimiento de tierras y el acceso a recursos naturales críticos.

A su vez, el turismo, tal como han señalado varios autores, funciona como "punta de lanza" del capitalismo ingresando a los territorios que han quedado aún fuera de este sistema a través de sus especificidades. Mediante el turismo, estos serían absorbidos por su lógica, inhibiendo el surgimiento de lógicas alternativas a la hegemónica (Dachary \& Arnaiz, 2004) que tendrían el potencial de subvertir algunas situaciones históricas de injusticia para con los pueblos originarios. Hale nos advierte que es necesario que los movimientos indígenas se detengan a reflexionar sobre los límites y los riesgos de este tipo de políticas basadas en el reconocimiento cultural de la diversidad indígena pues el hecho de que el "indio permitido" -es decir, el indígena no problemático y legitimado por estas políticas- se genere desde el Estado implicaría el inicio de una nueva forma de gobernar en América Latina. El reto, para los movimientos indígenas, consiste en desarrollar nuevas y creativas formas de resistencia a esta manera novedosa de sometimiento. 
Hale (2004) reconoce, sin embargo, que en algunos casos la resistencia cultural también podría fomentar la unidad política y establecer una base para que diversos agentes indígenas continúen sus luchas. Siguiendo este razonamiento, y teniendo en cuenta que la actividad turística es un catalizador o vehiculizador de las identidades y de procesos de reelaboración étnica, el turismo tendría la potencialidad también de resignificarse y transformarse, para las comunidades, en un arma a esgrimir apelando a la cultura. Podría incluso desafiar los modelos de desarrollo hegemónicos, en particular en contextos de avance de la frontera productiva capitalista que pone en peligro la subsistencia de estos pueblos. Ejemplo de esto son los discursos y los relatos de "la otra historia" que diversos guías elaboran durante los recorridos turísticos poniendo énfasis en la historia de despojo territorial y negación de derechos por parte del Estado a los pueblos originarios ${ }^{17}$.

Este es recién un inicio. La actividad turística, su relación con los pueblos originarios y las políticas públicas, está en sus albores, al igual que la preocupación por investigar estas problemáticas emergentes así como sus consecuencias. Podríamos abrir infinidad de preguntas para cerrar este artículo, pero nos conformaremos solo con algunas: ¿cuál es el rol de la cultura en la construcción de estas políticas turísticas indigenistas? ¿Construyen nuevas formas de gubernamentalidad más sutiles para los pueblos originarios, tal como señala Hale (2004)? ¿Cómo operaría el uso de este concepto en las instancias de diseño e implementación de estas políticas mediante la acción de distintos actores, teniendo en cuenta las diversas escalas del territorio? (es decir, desde el nivel nacional hasta desembarcar en el ámbito local). Será relevante, en esta instancia, detenerse a estudiar el rol clave de los técnicos que trabajan en el territorio y hacen de interfaz en los procesos de diseño y, sobre todo, de implementación de estas políticas en contextos de menor escala (municipal y local).

Finalmente, resulta ineludible cuestionarse, como contracara, qué estrategias, resistencias, reinterpretaciones y resignificaciones de estas políticas, desde lo que es el turismo rural comunitario y la propia cultura, realizan los diversos actores que son sus beneficiarios, teniendo en cuenta su desempeño en las diversas escalas. Resulta especialmente relevante focalizarnos en las comunidades de pueblos originarios y/o campesinas que participan o no en la RATuRC y en las organizaciones y los movimientos indígenas y campesinos para observar cómo operarían los procesos de reelaboración cultural en este contexto de actividad turística y evaluar la potencialidad que dicha actividad tendría eventualmente en las luchas por los reclamos históricos de estos pueblos.

Sondear los diversos significados de lo que es el TRC para todos los actores que participaron y aún participan en el desarrollo de esta modalidad turística es un desafío pendiente que podrá echar luces no solo sobre nuevas formas de gubernamentalidad, sino también sobre otras maneras de resistir que se presentan en el territorio ante este conjunto nuevo de tecnologías de poder. 


\section{Notas}

${ }^{1}$ Este artículo se enmarca en la investigación en curso de mi tesis de Maestría en Políticas Ambientales y Territoriales (FFyL, UBA) en elaboración. Es una primera aproximación al caso de la política pública turística e indigenista de alcance nacional en Argentina y describe el contexto de su surgimiento. El foco está puesto, en esta etapa, en el accionar del Estado, dado que la investigación tiene una perspectiva que va de lo macro a lo microsocial. Es decir, parte del análisis de la política a escala nacional para ir desentrañando el accionar del Estado en otras escalas hasta desembarcar, finalmente, en la escala local, la del lugar de la cotidianeidad de las comunidades originarias y/o campesinas. No desconocemos la complejidad que impregnan los diseños y la implementación de las políticas públicas. Estos procesos involucran a múltiples agentes que inciden en las diversas escalas de gobierno en forma dispar y que manifiestan resistencias, resignificaciones y reinterpretaciones de las políticas públicas que los afectan o involucran. En este caso mencionamos a aquellos que conforman y a los que afecta el funcionamiento de la RATuRC: personas pertenecientes a los pueblos originarios (sean estos emprendedores, líderes y/o miembros de organizaciones o movimientos indígenas o campesinos); funcionarios estatales y paraestatales (especialmente los técnicos que trabajan en terreno); empresarios turísticos privados (agentes de viaje y otros prestadores de servicios); etc. Estos temas serán complejizados a futuro en la tesis de maestría. Se agradece sinceramente los siempre atinados y certeros comentarios y la colaboración desinteresada de la licenciada Patricia Torres Fernández durante el proceso de escritura de este artículo.

${ }^{2}$ De aquí en adelante mencionaremos a este proyecto como proyecto RATuRC que es como se lo conoce hasta la actualidad.

${ }^{3}$ Esta afirmación no deja de reconocer que existieron momentos menos hostiles desde las políticas indigenistas para con los pueblos originarios. Sin embargo, y a pesar de esas instancias de mayor calma, las relaciones interétnicas en Argentina estuvieron históricamente cargadas de tensiones, con o sin conflicto manifiesto, dependiendo del período a considerar.

${ }^{4} \mathrm{Si}$ bien, tal como señalamos, las relaciones interétnicas en Argentina, desde el proceso de construcción del Estado-nación, han puesto a los pueblos originarios en una situación de dominación y subordinación, esto no implica que ellos asumieran un rol pasivo ni se constituyeran en meros receptores ante la implementación de las políticas indigenistas. Tal como señala Lenton (2015), ya a partir de la década de 1960 comenzaron a crearse organizaciones indígenas locales que se caracterizaron por tener un modo propio de hacer política, diferente al hegemónico. Se crearon federaciones nacionales e internacionales indígenas para canalizar diversos reclamos y demandas, sobre todo atinentes a la tierra, los derechos culturales y la representación política. Por otro lado, diversas organizaciones y movimientos indígenas comenzaron también a disputar al Estado y a la academia la autoridad de enunciación sobre la voz de los pueblos originarios, preparando con ello el terreno para la militancia y la política indígena posdictadura. Esta última se fortalece en la década de 1980 con el retorno de la democracia al país, que estuvo enmarcado por las transformaciones evidenciadas en Latinoamérica que Bengoa (2009) denominó una "segunda etapa de emergencia étnica". En Argentina, estos movimientos recibieron también la influencia de otras luchas indígenas, como las del Ejército Zapatista de Liberación Nacional (EZLN), la Confederación de Nacionalidades Indígenas del Ecuador (CONAIE) y las Primeras Naciones de Canadá (AFN) y algunas internacionales, como la Coordinación de Organizaciones Indígenas de la Cuenca Amazónica, entre otras. En 2003 se crea finalmente una organización nacional indígena: la Organización de Naciones y Pueblos Indígenas en Argentina (ONPIA) (Cuyul \& Davinson, 2007) .

${ }^{5}$ Durante los talleres de calidad se presenciaron numerosas discusiones por lo bajo y a escondidas de funcionarios y capacitadores en las que se cuestionaba lo que para los emprendedores era un servicio de calidad, manifestándose con ello una interesante disputa de saberes, sobre todo en cuanto a la manipulación y la conservación de los alimentos, a propósito de las cuales los emprendedores originarios se negaban a adoptar algunas técnicas que reemplazarían a las tradicionales por considerarlas parte de los saberes culturales que debían conservarse y compartir "enseñándoselos" a los turistas.

${ }^{6}$ Datos obtenidos en entrevistas a diversos funcionarios de distintas instituciones estatales vinculadas a la RATuRC.

${ }^{7}$ Dicho proyecto no logró aún llegar a discutirse en el Congreso de la Nación.

${ }^{8}$ Datos obtenidos en entrevistas a futuros emprendedores de TRC en el IV Encuentro Nacional de TRC de Pozo del Arbolito en 2017.

${ }^{9}$ En 2018, durante la administración M. Macri, el Ministerio de Turismo de la Nación desciende a Secretaría de Turismo.

${ }^{10}$ Resaltamos la importancia de los técnicos que trabajan en terreno, que establecieron relaciones de confianza y respeto mutuo con las instituciones y los funcionarios provinciales y con las comunidades con las que trabajan. Destacamos el grado de compromiso con el que continúan colaborando con las comunidades que asesoraban con anterioridad, a pesar de su actual desvinculación de la planta del Estado. Esto último no implica que no hayan puesto todo el capital social adquirido con anterioridad para gestionar el financiamiento del V Encuentro Nacional, logrando incluso obtener el apoyo del sector privado y de la provincia para financiar gran parte de este evento.

${ }^{11}$ Vale aclarar que esta fundación fue creada por técnicos pioneros en la RATuRC antes de finalizar la gestión 2003-2015 para garantizar y defender su trabajo ante la precariedad laboral de sus contratos y sostener el proyecto frente a la fragilidad y la escasa continuidad de este tipo de políticas públicas frente a los cambios de gestión políticos, tal como lo observa De la Maza para el caso chileno (2018)

${ }^{12} \mathrm{Si}$ bien entendemos que en este apartado hay mucha información que merece ser profundizada y complejizada, esta no será 
material de análisis de este artículo, que es meramente introductorio al análisis del caso. En esa situación están, por ejemplo, el rol de los funcionarios públicos -sobre todo de los técnicos en territorio-que median y hacen de interfaz (Long, 2001, cit. en De la Maza, 2018) durante el proceso de diseño e implementación de las políticas, al operar en diversas escalas y negociar entre las acciones estatales y las demandas ciudadanas; las relaciones de poder que se establecen en los encuentros y las capacitaciones en las que se desenmascaran juegos específicos de relaciones de poder-saber; la caracterización de la forma de gubernamentalidad que se pone en juego; la focalización puesta en la diferenciación entre los discursos y las prácticas estatales, así como las discusiones y los debates de los beneficiarios de estas políticas que resisten, impugnan, resignifican y reinterpretan su contenido y significado en diversas escalas del territorio. Estas discusiones no se desconocen y serán problematizadas durante el proceso de investigación en curso.

${ }^{13}$ El ordenamiento territorial es un instrumento de articulación transversal e interinstitucional que objetiva una planificación integrada y espacializada de acción de poder político. Su meta es la compatibilización de las políticas y sus secuelas en el espacio, evitando conflictos de directrices en el uso de los lugares y los recursos. En su marco se piensa al Estado como agente regulador y armonizador $y$ no como un generador de impactos negativos (sociales, ambientales y económicos) (Massiris, 2008).

${ }^{14}$ Vale aclarar que las "políticas estratégicas" son caracterizadas como un proceso creativo que sienta las bases de una actuación integrada a largo plazo; que establece un sistema continuo en la

\section{Bibliografía}

Arroyo, M. (2005). La división territorial del trabajo y la reorganización de los territorios nacionales. Geopolítica y economía geopolítica. Estado, poder y la reorganización de los territorios nacionales № 8(p 8) San Pablo.

Baines, S. G. (2012). Identidades e protagonismo política indígena no Brasil após a Constitução Federal de 1988. En Pimienta, J. \& Smilianic, M. (Orgs.), Etnología indígena e indigenismo (pp. 31-51). Brasilia: Positiva.

Baines, S. G. \& Lustosa, I. da C. (2015). Reelaboração étnico-cultural dos "Tremembé da Barra do Mundaú" frente ao turismo. Resinificacoes identitarias e festas. Oliveira, M., Pereira, R. M., D’Abadia, M. I. \& Curado, J. G. T. (Orgs.), Festas, religiosidades e saberes do Cerrado. Goiânia: Universidad Federal de Goiás.

Balbi, F. (2003). La lealtad antes de la lealtad: honor militar y valores políticos en los orígenes del peronismo. En Rosato, A. \& Balbi, F., Representaciones sociales y procesos políticos: estudios desde la antropología social. Buenos Aires: Antropofagia.

Balbi, F. \& Boivin, M. (2008). La perspectiva etnográfica en los estudios sobre políticas, Estado y gobierno. Cuadernos de Antropología Social, (27), (pp.7-17). toma de decisiones que comporta riesgo; que identifica cursos de acción específicos; que formula indicadores de seguimiento sobre los resultados y que involucra a los agentes sociales y económicos locales a lo largo del proceso. La planificación estratégica permite evaluar, así, permanentemente, la implementación de las políticas y redireccionarlas en caso de considerarse necesario, otorgándole agilidad a las tomas de decisión.

${ }^{15}$ A pesar de la creación de diversos instrumentos para atender a la denominada, desde el Estado, "cuestión indígena", los recursos asignados -tanto humanos como financieros- fueron insuficientes para lograr los propósitos enunciados en los diversos documentos que mencionamos (Cuyul \& Davinson, 2007). De esto resultó que muchos pueblos originarios quedaran en una situación muy vulnerable ante el cambio de gestión que se produjo en 2015. La nueva gestión incrementó sustantivamente esa vulnerabilidad con sus políticas francamente neoliberales.

${ }^{16}$ En Argentina hablar de "campo", en sentido común, es referirse al espacio rural.

${ }^{17}$ Se han observado, durante el trabajo de campo, visitas guiadas realizadas en la comunidad de Ocumazo, en Jujuy; en Quilmes y Amaicha del Valle, Tucumán, y en San Carlos, en la provincia de Salta, que abundan en relatos que dan cuenta de los procesos de las luchas indígenas por el reconocimiento de derechos y que ponen énfasis tanto en la historia de desposesión y despojos de las tierras y los recursos como en la exclusión de otros tipos de derechos, como los políticos, los culturales y los socioeconómicos.

Bechis, M. (1992). Instrumentos para el estudio de las relaciones interétnicas en el período formativo y de consolidación de Estados nacionales (pp. 82-111). En Hidalgo, C. \& Tamagno, L. (Comps.), Etnicidad e identidad. Buenos Aires: Centro Editor de América Latina.

Bell, D. (2006). Variations on the Rural Idyll. En Cloke, P., Marsden, T. \& Mooney, P. (Comps.), Handobook of Rural Studies (pp. 149-160). Londres: SAGE.

Bengoa, J. (2009). ¿Una segunda etapa de emergencia étnica en América Latina? Cuadernos de Antropología Social, (29), (pp.7-22).

Bertoncello, R. (2009). Presentación. En Bertoncello, R. (Comp), Turismo y geografía: lugares y patrimonio natural-cultural de la Argentina (pp. 5-15). Buenos Aires: Ciccus.

Boccara, G. (2007). Etnogubernamentalidad: la formación del campo de la salud intercultural en Chile. Chungara. Revista de Antropología Chilena, 39(2), (pp.185-207).

Bolados, P. (2009). ¿Participación o pacificación? La lógica neoliberal en el campo de la salud intercultural en Chile: el caso atacameño. Estudios Atacameños. Arqueología y Antropología Surandina, (38), (pp. 93-106).

Briones, C. (2005). Contextos globales, procesos nacionales y 
provinciales. En Briones, C. (Ed.), Cartografías argentinas: políticas indigenistas y formaciones provinciales de alteridad. Buenos Aires: Geaprona.

Briones, C. \& Carrasco, M. (2004). La lucha por la tierra: (neo) indigenismo estatal y las producciones indígenas en Argentina (1985-1999). En Cruz, E. \& Paolini, R. (Orgs.), La propiedad de la tierra: pasado y presente. Arqueología, historia y antropología sobre la problemática de la tierra en la Argentina (pp. 228-265). Anuario del CEIC 3/2003. Jujuy: Universidad Nacional de Jujuy.

Cáceres, C., Troncoso, C. \& Vanevic, P. (2013). Nuevas modalidades de turismo en Argentina: experiencias de turismo comunitario en Salta, Argentina. XII Jornadas de Investigación en Turismo IV Simposio "El turismo y nuevos paradigmas educativos". Usuahia.

Canet, V. (2006). El derecho de los pueblos indígenas en el Estado Argentino. Buenos Aires: Mimeo.

Castro, M. (2008). ¿ Reconocimiento o asistencialismo? Antropología de la negociación de un proyecto de turismo cultural indígena financiado por el Banco Interamericano de Desarrollo. (Tesis inédita en licenciatura en antropología). Universidad de Buenos Aires, Buenos Aires.

Castro, H. (2018). Lo rural en cuestión: perspectivas y debates sobre un concepto clave. En Castro, H. \& Arzeno, M. (Coords.), Lo rural en redefinición (pp. 19-48). Buenos Aires: Biblos.

Cardoso de Oliveira, R. (1992). Etnicidad y estructura social. México: Centro de Investigaciones y Estudios Superiores en Antropología Social.

Cuyul, A. \& Davinson, G. (2007). La organización de los pueblos indígenas en Argentina: el caso de la ONPIA. Argentina: Organización de Naciones y Pueblos Indígenas en Argentina, CUSO, Agencia Española de Cooperación Internacional, Universidad de La Frontera. Recuperado de http:/www.ts.ucr.ac.cr/bianrios/libros-000003.pdf

Dachary, C. \& Arnaiz, S. (2004). Turismo y globalización: ¿dos caras de una misma moneda? Estudios y Perspectivas en Turismo, (13), (pp. 303-315).

De Mattos, C. (1984). Paradigmas, modelos y estrategias en la práctica latinoamericana de planificación regional. Revista Latinoamericana de Planificación, (№ 89), (pp 5- 35) Guatemala, SIAP

García, A. \& Valverde, S. (2007). Políticas estatales y procesos de etnogénesis en el caso de las poblaciones mapuches de Villa la Angostura, provincia de Neuquén. Cuadernos de Antropología Social, (25), (pp. 111-132).

Gorosito, A. (2008). Convenios y leyes: la retórica políticamente correcta del Estado. Cuadernos de Antropología Social, (28), (pp. 51-65).

Gras, C \& Hernández, V. (coord.) (2009) La Argentina rural. De la agricultura familiar a los agronegocios. Buenos Aires. Biblos.

Gruenewald, R. de A. (2003). Turismo e etnicidade. Horizontes Antropológicos. Antropología e Turismo, 9(19), (pp. 141-159).

Gudynas, E. (2009). Diez tesis urgentes sobre el neoextractivismo: contextos y demandas bajo el progresismo sudamericano actual (pp. 187-225). En Schuldt, J. et al., Extractivismo, política y sociedad. Quito: Centro Andino de Acción Popular, Centro Latinoamericano de Ecología Social.

Hale, C. (2004) El protagonismo indígena, las políticas estatales y el nuevo racismo en la época del "indio permitido". Ponencia para la conferencia: "Construyendo la paz: Guatemala desde un enfoque comparado" organizado por la Misión de verificación de las Naciones Unidas en Guatemala (MINUUA) 27-29 de octubre.

Lacko, E. (2008). Procesos de re-adscripción étnica en Villa La Angostura: una visión hegemónica del conflicto territorial en contexto de explotación turístico. V Jornadas de Investigación en Antropología Social. Universidad de Buenos Aires, Buenos Aires.

(2011). Políticas nacionales de turismo e identidad en el nuevo Estado pluricultural: el proyecto RATuRC. $X$ Congreso Argentino de Antropología Social. Facultad de Filosofía y Letras de la Universidad de Buenos Aires, Buenos Aires.

(2019). Conflicto ambiental en Quebrada de Humahuaca: Patrimonio Natural y Cultural de la Humanidad, agro-ganadería tradicional, Turismo y... ¿minería uranífera? Un análisis de caso en la Provincia de Jujuy, Argentina (2007-2014). En Tancredi, E. \& Valverde, A. (Orgs.), Abordajes teórico-metodológicos de los conflictos socioambientales: propuestas para un debate interdisciplinario a partir de estudios de caso (pp. 151-180). Luján: Universidad Nacional de Luján.

Lattuada, S., Marques, S. \& Neme, J. (2012). Desarrollo rural y política. Buenos Aires: Ciccus.

Lenton, D. (2005). De centauros a protegidos: la construcción del sujeto de la política indigenista argentina desde los debates parlamentarios (1880-1970). (Tesis doctoral inédita). Universidad de Buenos Aires, Buenos Aires.

(2010). Política indigenista argentina: una construcción inconclusa. Anuario Antropológico/2009-1, (pp. 57-59).

(2015). Notas para una recuperación de la memoria de las organizaciones de militancia indígena. Identidades, (8), (pp. 117-154).

Lenton, D. \& Lorenzetti, M. (2005). Neoindigenismo de necesidad y urgencia: la inclusión de los pueblos originarios en la agenda del Estado neoasistencialista. En Briones, C. (Ed.), Cartografías argentinas: políticas indigenistas y formaciones provinciales de alteridad (pp. 293-329). Buenos Aires: Antropofagia.

Lustosa, I. M da C. (2012). Terra indígena Tremembé de Sao José e Buriti e o Nova Atlantida: afrimacao étnica no territorio disputado perlo turismo macico. En Lustosa, I. M. da C., Os povos indígenas, o turismo e o territorio: um olhar sobre os Tremembé e os Jenipapo-Kanindé do Ceará (pp. 173-220). (Tesis inédita de doctorado). Instituto de Estudios Socio-Ambientales, Universidad Federal de Goiás, Goiânia.

(2015). O turismo macico e o turismo comunitário em zonas costeiras do Brasil: povos indígenas do Ceará nas redes de turismo comunitário. Pasos, Revista de Turismo y Patrimonio Cultural, (8), ¿El turismo es cosa de pobres? Patrimonio cultural, pueblos indígenas y nuevas formas de turismo en América Latina, (pp 87-110).

Marchena, M. (s.f.). Un ejercicio prospectivo de la industria del turismo fordista al ocio de producción flexible. Sevilla: Mimeo.

Martínez, C. (2012). La política pública indígena en la Argentina: apuntes sobre el derecho a la tierra y a la organización. Revista de 
Debate Político. Reflexión de Trabajo Social. Artículos seleccionados, 2 (4), (pp. 1-10) Disponible en el Repositorio Digital Institucional de la Universidad de Buenos Aires: <http://trabajosocial.sociales.uba. ar/wp-content/uploads/sites/13/2016/03/15_Martinez.pdf>

Massiris, A. (2008). Gestión del ordenamiento territorial en América Latina: desarrollos recientes. Conferencia Magistral en el IV Seminario Intenacional de Ordenamiento Territorial. Encuentro Interdisciplinario". Organizado por el Institiuto CIFOT, Facultad de Filosofía y Letras de la Universidad Nacional de Cuyo, Mendoza. Disponible en: http://bdigital.uncu.edu.ar/objetos_digitales/3238/ massirisproyeccion4.pdf

Maza, F. de la (2018). Gobierno local, política y turismo indígena: enfoque etnográfico en contextos interculturales. Antropologías del Sur, (5). (pp.199-213).

Meethan, K. (2001). Tourism in Global Society, Place, Culture, Consumption. Basingstoke, Hampshire y Nueva York: Palgrave.

Molina, S. (2000). El posturismo: de los centros turísticos industriales a las ludópolis. México: Tesis Económicas Profesionales.

Moncayo, E. (2001). Evolución de los paradigmas y modelos interpretativos del desarrollo territorial. Santiago: Instituto Latinoamericano y del Caribe de Planificación Económica y Social.

Nouzeilles, G. (2002). Introducción. En Nouzeilles, G. (Comp.), La naturaleza en disputa: retóricas del cuerpo y el paisaje en América Latina (pp. 11-38). Buenos Aires: Paidós

Pacheco de Oliveira, J. (2004). A Viagem da Volta: etnicidade, política e reelaboracao cultural do nordeste indígena, $2^{\mathrm{a}}$ ed. Río de

\section{Fuentes}

Política y Estrategia Nacional de Desarrollo y Ordenamiento Territorial (PENDOT) (2016) Ministerio de Planificación Federal, Inversión Pública y Servicios.

Plan Estratégico Territorial (PET) (2008) Poder Ejecutivo Nacional. Ministerio de Planificación Federal, Inversión Pública y Servicios. Buenos Aires. http://www.planificacion.gob.ar/documentos/publicaciones/id.noticia/3001

Plan Estretégico Territorial (PET) Avance II. (2011). Ministerio de Planificación Federal, Inversión Pública y Servicios. Buenos Aires. http://www.planificacion.gob.ar/documentos/publicaciones/ id.noticia/2858

Ley Nacional de Turismo 25.997/2004

Plan Federal Estratégico de Turismo Sustentable (PFETS) 2016. Ministerio de Turismo de la Nación.

Programa Turismo en el Espacio Rural de la República Argentina TERRA (2010) Programa de Destinos y Productos Turísticos para el Desarrollo de la República Argentina. Ministerio de Turismo de la Nación.

PROYECTO: Red Federal de Turismo Comunitario en ámbitos rurales (2008). Argentina Plan Federal Estratégico de Turismo
Janeiro: Contra Capa, LACED.

Pelliza, V., Pérez, M. \& Ercolani, P. (2012). Políticas públicas, desenvolvimento e turismo rural. Gestión pública del turismo rural comunitario en la República Argentina. IX Congreso Internacional sobre Turismo Rural e Desenvolvimento Sutentável. San Pablo, Brasil.

Shore, C. (2010). Reflexiones sobre la "formulación" de las políticas. Antípoda, (10) (pp. 21-49). Recuperado de http://www. scielo.org.co/pdf/antpo/n10/n10a03.pdf

Subirats, J; Knoepfel, P; Larruje, C. \& Varone, F. (2008) Análisis y gestión de las políticas públicas. Barcelona. España. Ariel.

Troncoso, C. (2009). Patrimonio y redefinición de un lugar turístico: La Quebrada de Humahuaca, Provincia de Jujuy, Argentina. Estudios y Perspectivas en Turismo, (18). (pp144-160).

Urry, J. (1996). La mirada del turista. Lima: Universidad de San Martin de Porres.

Valverde, S. \& García, A. (2007). Políticas estatales y procesos de etnogénesis en el caso de las poblaciones mapuches de Villa la Angostura, provincia de Neuquén, Argentina. Cuadernos de Antropología Social $N^{\circ} 25$. (pp 111-132) FFyL-UBA- ISSN: 0327-3776

Velázquez, F. (2018). La valoración turística del campo. En Castro, H. \& Arzeno, M. (Coords.), Lo rural en redefinición: aproximaciones y estrategias desde la geografía (pp. 253-280). Buenos Aires: Biblos.

Winter, C. \& Zusman, P. (2018). Las áreas rurales y el patrimonio histórico y cultural. En Castro, H. \& Arzeno, M. (Coords.), Lo rural en redefinición: aproximaciones y estrategias desde la geografía (pp. 231- 252). Buenos Aires: Biblos.

Sutentable. Dirección Nacional de Desarrollo turístico. Ministerio de Turismo de la Nación.

RATuRC Guía Red Argentina de Turismo Rural Comunitario (2012). Ministerio de Turismo de la Nación; Ministerio de Agricultura, Ganadería y Pesca de la Nación y Ministerio de Desarrollo Social de la Nación. Ciudad Autónoma de Buenos Aires. Ediciones INTA, PRONATUR, Min de Desarrollo Social. Buenos Aires.

Documento Interno 1. "Política públicas para el Desarrollo del Turismo en el Espacio Rural de la República Argentina" (2012) Comisión de Trabajo Interministerial para el Desarrollo Turístico con Inclusión Social en el Espacio Rural" Convenio marco de cooperación entro los Ministerios de Turismo, Agricultura, Ganadería y Pesca, Desarrollo Social y Trabajo, Empelo y Seguridad Social de la Nación.

Documento Interno 2. "Conformación de la Comisión Interministerial para el Desarrollo turístico en el Espacio Rural con Inclusión Social y Plan de Trabajo para el Desarrollo del Turismo Rural en la República Argentina" (2013) Convenio marco de cooperación entro los Ministerios de Turismo, Agricultura, Ganadería y Pesca, Desarrollo Social y Trabajo, Empelo y Seguridad Social de la Nación. 